\title{
Obesity, diabetes mellitus and last but not least, osteoporosis
}

\author{
Obesidade, diabete melito e osteoporose
}

Francisco J. A. de Paula ${ }^{1,2}$, Clifford J. Rosen ${ }^{2}$

\section{SUMMARY}

${ }^{1}$ Departamento de Medicina Interna, Faculdade de Medicina de Ribeirão Preto, Universidade de São Paulo (FMRP-USP),

Ribeirão Preto, SP, Brasil ${ }_{2}$ Maine Medical Center Research Institute, Scarborough, ME, Estados Unidos

Correspondence to: Clifford J. Rosen

Maine Medical Center Research Institute, 81

Research Drive

04074-7205 - Scarborough, ME

Estados Unidos

rosenc@mmc.org

Received on Nov/16/2009

Accepted on Jan/28/2010
Knowledge about the influence of bone on intermediary metabolism corresponds to a developing area that has gained prominence. The old concept of bone and adipose tissues as inert metabolic tissues, with minor contributions to metabolic adaptations has been reconsidered in light of findings that bone is involved in the development of insulin sensitivity. Similarly adipose tissue exerts important influences on bone mass development and maintenance. Moreover, the use of drugs in the treatment of metabolic disorders such as diabetes mellitus can impact bone metabolism. These networks linking osteoporosis to obesity and diabetes mellitus have reinvigorated investigations in the pathophysiology of osteoporosis. The present review examines this aspect and calls attention to health care providers and potential treatments of skeletal disorder. Arq Bras Endocrinol Metab. 2010;54(2):150-7

\section{Keywords}

Osteoporosis; obesity; diabetes mellitus; bariatric surgery; thiazolidinediones

\section{SUMÁRIO}

O estudo sobre a influência do tecido ósseo no metabolismo intermediário corresponde a uma área em desenvolvimento que tem ganho recente destaque. 0 conceito prévio de que os tecidos ósseo e adiposo seriam metabolicamente inativos foi reconsiderado à luz de estudos que mostram que metabólitos ósseos podem influenciar a sensibilidade à insulina. Da mesma forma, o tecido adiposo exerce influência importante no desenvolvimento e na manutenção da massa óssea. Além disso, o uso de drogas no tratamento de doenças metabólicas como o diabetes melito pode afetar o metabolismo ósseo. A rede de conexões existentes que ligam a osteoporose à obesidade e ao diabetes melito tem revigorado investigações sobre a fisiopatologia da osteoporose. A presente revisão analisa esse aspecto e destaca a necessidade de atenção para esses pontos por parte de serviços de saúde voltados para o atendimento de diabetes melito e da obesidade quanto ao potencial impacto sobre o tecido ósseo. Arq Bras Endocrinol Metab. 2010;54(2):150-7

\section{Descritores}

Osteoporose; obesidade; diabetes melito; cirurgia bariátrica; tiazolidinediona

\section{INTRODUCTION}

$\mathrm{H}_{\mathrm{t}}^{\mathrm{w}}$ uman being image has changed significantly in the last fifty years due to the evolving tendency to increase in body weight. Obesity, the metabolic disorder characterized by excessive fat storage reflects the imbalance between energy intake and expenditure. The epidemic characteristic of the disturbance can be verified by the impressive $100 \%$ increase in the rate of obese people in the USA in data from the period of 1976-1980 (15\% of adult population) toward $1999-2002$ (31\% of adult population) (1). Data obtained in South America were similar since in Brazil the increase in obesity rate was $92 \%$ in men and $63 \%$ in women from 1975 toward 1989 (2).

Diabetes mellitus (DM) is a heterogeneous metabolic disorder characterized by the presence of hyperglycemia. Recent data indicate that $12.9 \%$ of the adult U.S. population aged $\geq 20$ years have DM, of which $39.8 \%$ is undiagnosed (3). A national survey conducted in Brazil two decades ago showed a DM prevalence of 7.6\%, 
which was similar to other Western countries for the same period (4). Type 2 DM (T2DM) comprises $90 \%$ of all cases of DM syndrome. A major risk factor for developing T2DM is excessive adiposity.

Bone loss and degenerative changes of bone characteristics are a progressive process occurring after maturity. Therefore, the increase in life expectancy places osteoporosis as one of the major health public problems in the world. Among US population aged more than 50 years, 10 million have osteoporosis (5). In a recent Brazilian population-based study the prevalence of fragility fracture in women and men aged higher than 40 years were 15.1 and $12.8 \%$, respectively $(6)$.

Insulin resistance, the central metabolic disturbance associated with fat accumulation, is linked to metabolic (i.e. increased free fat acids and hypertriglyceridemia), endocrine (i.e. increased glucocorticoid and androgens) and pro-inflammatory (i.e. cytokines and tumor necrosis factor) alterations. During the last decade, the role of adipose tissue as an exclusive site of energy storage has shifted to one that is an endocrine source of active modulators of insulin sensitivity such as leptin, adiponectin, resistin and cytokines. Furthermore, visceral adipose tissue has an increased lipolytic activity and releases FFA swiftly to the liver and pancreas, thereby provoking lipotoxicity. Insulin, as well as those adipose tissue factors, also influences bone remodeling.

Recently, investigators have identified polypeptides such as osteocalcin and osteopontin, which can also modulate insulin sensitivity (7). These new networks link metabolic disturbances to osteoporosis in a new bidirectional pattern. The clinical impact of this association cannot be currently predicted due to the heterogeneity of each disorder. However, it cannot be neglected, particularly since one of the most promising groups of drugs to treat diabetes (thiazolidinediones) can induce bone fragility. In the present review we discuss several aspects of the relationship between hard and soft tissues. The clinical association between osteoporosis, obesity and DM and its mechanisms are contemplated, our principal focus is to call attention to the potential reciprocal relationship of these common diseases.

\section{OSTEOPOROSIS AND OBESITY}

Previous studies showed that body weight correlates positively with bone mineral density. In addition, rapid weight loss by severely obese individuals can induce bone loss, as high as 10 percent in the femoral neck, one year after bariatric surgery (8). Notwithstanding the evidence suggesting a beneficial effect of adipose tissue on bone maintenance, other data argue against this effect. A large population-based study in China did not verify positive correlation between bone mass and fat mass (9). Similar results were obtained in adolescents and young adults of both sexes (10).

Bone mineral density (BMD) alone, although currently considered the strongest single factor correlated to risk of fracture, does not permit a comprehensive recognition of fracture risk. There are several other independent factors contributing to fracture risk (age, glucocorticoid therapy, previous fracture, smoking, alcohol abuse, and rheumatoid arthritis). Also, low body mass index (BMI) only affects the risk of fracture independently of BMD in the case of hip fracture, most likely through an association with frailty and increased risk of fall (11).

Population-based studies revealed that less than a half of the people with a sustained fragility fracture have BMD values below the threshold established by the WHO report as osteoporosis (12-13). Consequently, the majority of fractures that occur in individuals is classified at most as osteopenic. Also, a significant number of individuals have osteoporotic fractures despite a normal T-Score (12-13). In addition to revealing the limitations of BMD measurements these data highlight the important contribution of independent risk factors to fracture risk.

Evidence showing an association between obesity and fracture were acquired in a pediatric clinical investigation. The study exhibited higher forearm fracture incidence in obese children compared with normal weight, age-matched individuals. Recently, more compelling data was obtained by Premaor and cols. (14), when they audited the profile of patients aged less than 75 years, attending the Liason Fracture Service, in the United Kingdom, with a fragility fracture (14). Approximately, $40 \%$ of this group had normal BMD and more than $50 \%$ were obese or morbidly obese patients. Within the obese and morbid obese patient subgroups $80 \%$ and $89 \%$ had normal value of BMD T-Score of total hip. Thus, these results confirm the tenet that obesity has a protective role on BMD, but at the same time suggest the occurrence of high fracture risk in this population (Figure 1).

Furthermore, there are several clinical conditions in which weight gain occurs with parallel bone loss (15). The physiological changes associated with menopause in- 


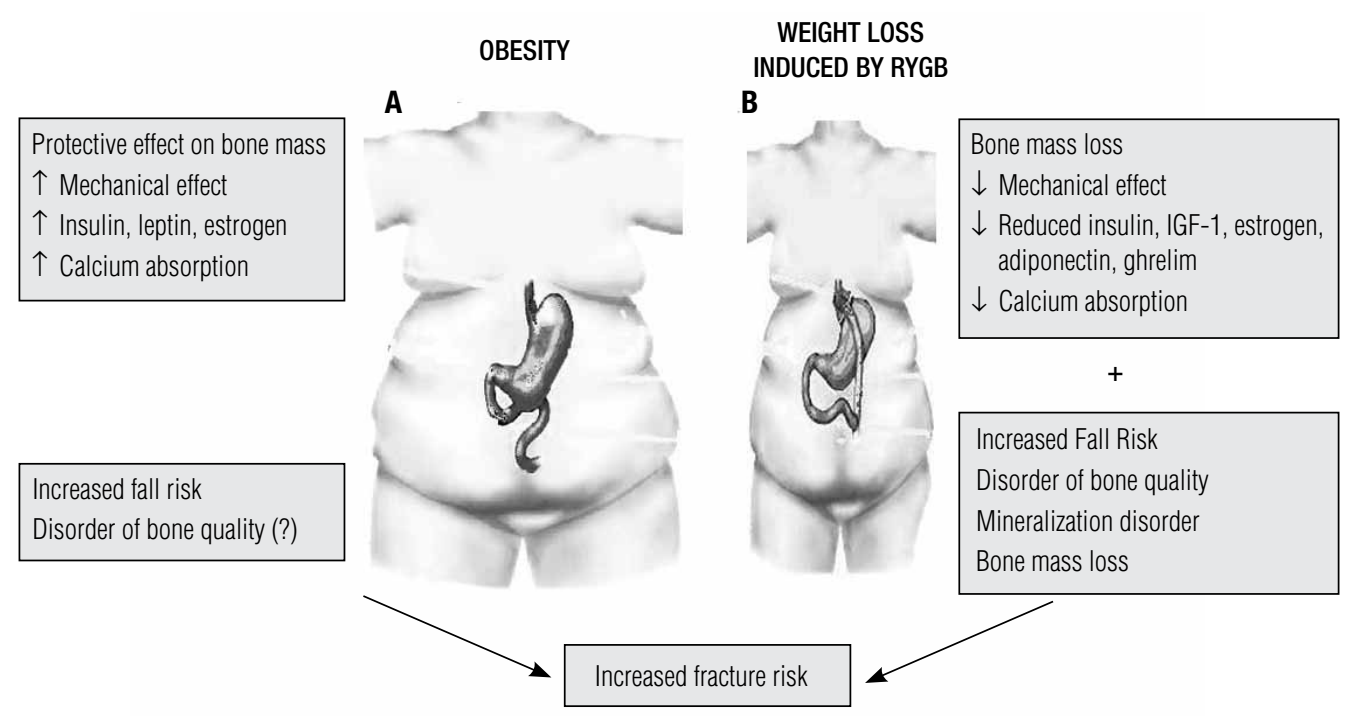

Figure 1. (A) Pathophysiology of the increased fracture risk in obesity. (B) Pathophysiology of bone loss and of the increased fracture risk associated to weight loss after bariatric surgery.

clude fat accumulation on one side and bone catabolism on the other. The same pattern is observed in hypercortisolism. Another circumstance emerged with the use of activators of the PPAR $\gamma$ (thiazolidinediones) for the treatment of T2DM. At the same time patients using these drugs experience decrease in blood glucose levels and gain weight due to the increase in peripheral adipose tissue. Clinical investigations showed bone loss and higher rates of fracture in diabetics using rosiglitazone compared to others on metformin or glyburide (16). Coincidentally with bone loss associated with glucocorticoids and aging, rosiglitazone enriches bone marrow fat while bone volume is reduced. Thus, like insulin resistance which has visceral fat as a marker; fat allocation in bone marrow is an indicator of osteoporosis. While the waist to hip rate is a surrogate identifier of obesity linked to insulin resistance, currently there is no clinical means to distinguish the obese patient associated with osteoporosis.

\section{Osteoporosis and obesity treatments}

Independent of its influence on skeleton, obesity is associated with several major health problems and has a strong psychological impact. Hypertension, DM and dyslipidemia are all closely associated to obesity and together increase significantly the risk of cardiovascular disease (17). Obese patients also have increased risk to develop breast, colon, prostrate and endometrial cancer (17). Moderate weight loss is an efficient way to prevent the risk to develop DM in overweight and obese individuals, while drastic weight loss ameliorates the expectancy of life of severely obese patients. Thus, weight loss is pursued by patients and encouraged by physicians to decrease the risk of cardiovascular disease and related disorders. However, the quality of life of a considerable number of these patients can be affected, since the consequences of weight loss on body composition is not limited to adipose tissue. Bone tissue seems exquisitely sensitive to decrements in body weight.

Previous studies have shown that even 10\% weight loss can induce about $2 \%$ bone loss $(18,19)$. The impact can be higher in individuals exposed to more intense and rapid weight loss (20) compared to moderate decrement in weight and for longer periods (21).

Unfortunately, the clinical management of obesity based on changes in life style habits has yielded frustrating results on a long-term basis. This is largely due to the slow process of weight loss and to the need for strong involvement and effort on the part of the patient that should last throughout life. The need to develop therapeutic options whose efficacy is less dependent on the patient's determination and the challenging effort to change habits has favored the use of gastric reduction surgery as a desirable alternative. Weight loss evolves rapidly, and currently bariatric surgery has increasingly become recognized as a highly effective alternative for achieving major weight reduction for obese patients. A large prospective cohort study [Swedish Obese Subjects (SOS) study] found that weight loss was still apparent 10 years following surgery, whereas patients receiving conventional treatment had gained weight (22). 
The Roux-en-Y gastric bypass (RYGB) procedure combines restriction and malabsorption techniques, creating both a small gastric pouch and a deviation of a segment of the small intestine. Presently, RYGB is the most frequent and efficient surgery option to treat severe obesity and will be the only one we will discuss in the present review.

Patients may be at risk of postgastrectomy bone disease. Metabolic bone disease is a well-documented long-term complication of obesity surgery. It is often undiagnosed, or misdiagnosed, because of lack of physician and patient awareness. Abnormalities in calcium and vitamin $\mathrm{D}$ metabolism begin shortly after gastrointestinal bypass operations; however, clinical and biochemical evidence of metabolic bone disease may not be detected until many years later. RYGB can potentially be associated to two metabolic bone disorders osteomalacia and osteoporosis. Isolated cases of osteomalacia in patients submitted to gastric bypass for morbid obesity treatment have been published in the last few years, resembling old cases of osteomalacia after gastric resection for management of peptic ulcer $(23,24)$. While severe osteomalacia seems a latter and less frequent complication, bone loss appears to be an early effect on almost all patients submitted to RYGB (Figure 1).

\section{Osteometabolic changes after Roux-en-Y gastric bypass}

Vitamin D has an important role in calcium absorption. Estrogen levels, dietary intake, age and body weight also influence calcium absorption. True fractional calcium absorption can be approximately $10 \%$ higher in severely obese patients compared to overweight individuals, most likely as a result of higher estrogen levels and increased gastrointestinal mucosal surface (25). Thus, RYGB has significant impact on calcium and vitamin $\mathrm{D}$ metabolism. Diet restriction reduces the exogenous load of calcium and vitamin D and decreases intake of macronutrients that positively affect their absorption. In RYGB, the proximal jejunum is bypassed, excluding an important site of calcium absorption, which contributes to the decreased calcium load. Additionally, the reduction in food intake leads to increased release of cortisol and decrease in IGF-I serum levels, both adaptations potentially impair calcium absorption (25) (Figure 1).

Adipose tissue shrinkage modifies the adipocyte secretion profile. Whereas leptin declines, adiponectin increases after weight loss, though the impact of these changes on bone remodeling is still to be understood. Leptin induces bone loss indirectly by the central stim- ulation of the sympathetic system, but acts directly on osteoblasts, stimulating bone formation. Conflicting results have been obtained on clinical investigation about bone effects of adiponectin, suggesting neutral, positive or negative association to BMD. Estrogens, IGF-I and insulin fall after weight loss. Gastrointestinal hormones are other variables to be considered in the global evaluation of the weight loss impact on bone. Ghrelin, a stomach-derived peptide, increases during food deprivation to stimulate appetite. In contrast, weight loss due to gastric bypass produces significant reduction of ghrelin levels (25). Previous data have shown that ghrelin stimulates osteoblast proliferation and differentiation. Glucagon-like peptide-2 (GLP-2), an enteroendocrine L-cell derived hormone, is an inhibitor of gastric emptying. GLP-2 also decreases bone resorption (26) and has positive effect on bone mineralization (27). Overall, the nutritional, metabolic and hormonal changes produced by rapid weight loss favor bone resorption. Considering that obesity can be associated with fracture and that obesity treatment also can damage skeleton, it is reasonable to conclude that the primary target should be obesity prevention.

\section{Bone mineral density evaluation in obese patients}

The evaluation of BMD in obese patients by DXA is limited by the capacity of equipment to support and to measure individuals weighing more than $115-160 \mathrm{~kg}$, depending on the manufacturer. New machines can accommodate individuals of up to $180 \mathrm{~kg}$, but it is still insufficient to satisfy the current profile of obesity. The follow up of total body BMD during weight loss is confounded by variables such as fat density and distribution.

Peripheral BMD is the alternative suitable to evaluate bone mass in obese patients. Peripheral DXA measurements at phalanges and proximal/distal forearm have been shown in studies to correlate directly with BMD measurements of the spine and hip by central DXA. Quantitative ultrasound seems to be less closely correlated with hip and spine BMD by DXA.

\section{Management after RouX-en-Y gastric bypass}

Follow up includes careful examination to detect subclinical fracture. Patient stature should be measured before and at regular intervals after surgery. If necessary, vertebral fracture might be assessed by lateral spine radiograph. 
Patients undergoing RYBG should be screened for osteoporosis with bone density measurement. Laboratory evaluation includes calcium, albumin, magnesium, PTH and 25 $(\mathrm{OH}) \mathrm{D}$.

Operated patients should be encouraged to perform regular weight-bearing physical exercise. Recent data suggest increased fall risk in post-operative bariatric surgery patients (28). Thus, mechanical risks for falls should be addressed and physical activity is part of the strategy to reduce fracture risk.

Calcium and vitamin D supplementation should be prescribed in all bariatric patients. One should consider slightly higher doses than RDI recommendations: $1,500 \mathrm{mg}$ calcium and 2000 UI vitamin D. Check $25(\mathrm{OH}) \mathrm{D}$ serum levels every three months to ensure adequate levels. One should consider pharmacological treatment in patients if BMD is below -1.5. In patients with severe malabsorption parenteral administration may be more convenient.

\section{DIABETES MELLITUS AND OSTEOPOROSIS}

The term heterogeneous is correct in defining diabetes mellitus (DM) due to the large spectrum of variation in its etiopathogenesis and clinical manifestations. Almost certainly, the only rule valid to all diabetic patients is the tendency to hyperglycemia. Osteoporosis can be added to the large list of disorders associated to DM whose mechanistic association and magnitude of clinical impact have been hard to clarify. When BMD is used as surrogate indicator of osteoporosis, most data suggest that type 1 diabetes mellitus (TIDM) is linked to osteoporosis. Also, results from the Nord-Trondelag Health Survey from Norway showed a significant increase in hip fracture rates among female type 1 diabetic patients (relative risk 6.9, confidence interval 2.221.6) compared to nondiabetic female patients (29). However, the results are quite undefined in relation to T2DM, existing indications of bone loss, bone maintenance and protective effects on bone.

The differences between $\mathrm{Tl}$ and T2 DM are not surprising in view of that many unfavorable factors to bone present in the former are usually absent in the latter (Figure 2). Low body weight, hypoinsulinemia and low serum levels of IGF-I are common clinical and biochemical features of TIDM, which are not encompassed within T2DM (30). Poor glucose control is an etiological factor for the microangiopathic complications that develop in all DM types. Although there are data suggesting a higher bone loss rate in chronically hyperglycemic patients, hyperglycemia is not clearly linked to low bone mass in case of T2DM (31). However, bone mass is not the sole determinant of bone strength; other components (i.e., material properties, microdamage accumulation and bone microarchitecture) are important for bone quality and have critical role on bone propensity to fracture. Schwartz and cols. (31), in a large prospective study in older women obtained from the Study of Osteoporotic Fractures, confirmed that women with T2DM experience higher fracture rates in regions of the hip, humerus and foot than do nondiabetic women (31). DM affects protein

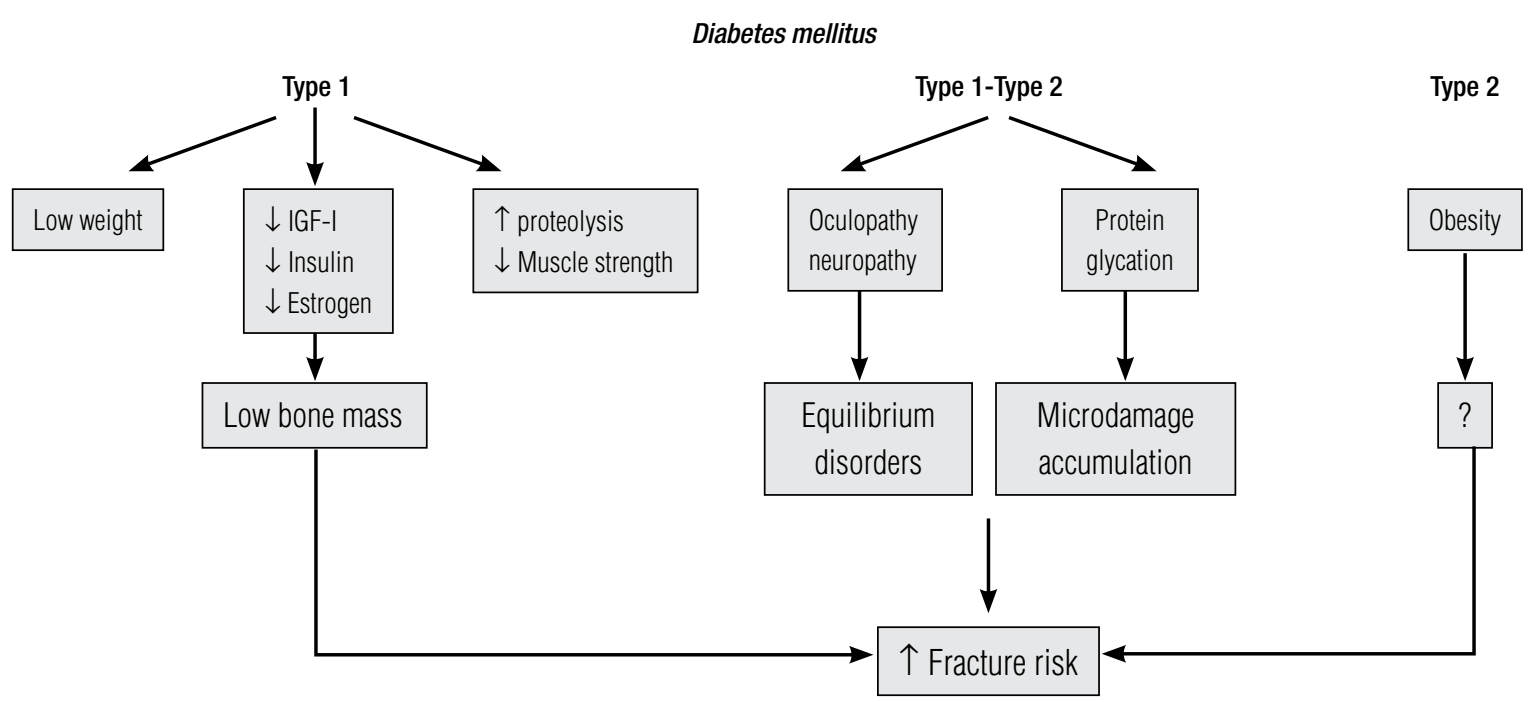

Figure 2. Pathophysiology of the increased fracture risk in type 1 and type 2 diabetes mellitus. 
metabolism and recent studies have shown impairment of muscle function and balance in diabetic patients. Therefore, diabetic patients have a greater susceptibility to fall and bone microdamage. Additionally, a wide range of pathogenic pathways have been proposed that underlie bone quality dysfunction in osteoporosis secondary to DM. Protein glycation is a common posttranslational modification of proteins induced by the spontaneous condensation of glucose and metabolic intermediates (e.g. triose phosphate, glyoxal and methyglyoxal) with free amino groups in lysine or arginine residues. This process leads to an irreversible formation of advanced glycation end products (AGE) from an array of precursor molecules (32). Alfa-oxaloaldehydes such as glyoxal, methylglyoxal (MGO) and 3-deoxyglucosone occur at high levels in diabetic plasma or are significantly elevated in cells exposed to high glucose concentrations (32). They can react directly with protein to yield intracellular and extracellular AGEs, which have been shown to have significant pathogenic effects in cells and tissues $(33,34)$. Collagen cross-linking, a major post-translational modification of collagen, plays important roles in the biological and biomechanical features of bone. Collagen cross-links can be divided into lysyl hydroxylase and lysyl oxidase-mediated enzymatic immature divalent cross-links, mature trivalent pyridinoline and pyrrole cross-links and glycation- or oxidation-induced non-enzymatic cross-links (advanced glycation end products) such as glucosepane and pentosidine. These types of cross-links differ in the mechanism of their formation and function, determining differences in the mineralization process as well as in the bone tendency to microdamage. Pentosidine is one of the well-known AGEs, and its concentration in cortical and trabecular bone is negatively associated with bone strength. Previous studies showed that patients with femoral neck fractures had higher concentrations of pentosidine in cortical (35) and cancellous bone (36) than in controls. In vitro, high glucose and AGEs synergistically inhibit the mineralization activity of MC3T3-El cells through glucose-induced increase in the receptor for AGE (RAGE) (37). Diabetic patients have significantly higher levels of serum pentosidine than control individuals. Furthermore, in a recent clinical study, Yamamoto and cols. (38) observed in a small group of patients that pentosidine serum levels were positively and significantly associated with the presence of vertebral fractures in postmenopausal women with $\mathrm{DM}$ and that this association was independent of BMD.
Thus, there is a dichotomy between BMD and fracture risk in type 2 diabetic patients. Obesity, as discussed above, and protein glycation are two contributing factors that increase the susceptibility to fracture in T2DM that are not reflected in bone mass measurement.

\section{Diabetes mellitus treatment and osteoporosis}

Results obtained in the DCCT and UKPDS studies showed that plasma glucose levels are directly implicated in the development of diabetic complications. Low plasma glucose levels were then pursued as a surrogate parameter for the most important objective in the treatment of DM, the prevention of chronic micro and macroangiopathic disorders.

Thiazolidenediones (TZD) were introduced as powerful glucose lowering agents that could reduce complications in T2DM. The first of these drugs, troglitazone, was withdrawn from the market because of hepatotoxicity. Rosiglitazone and pioglitazone, two other TZDs, are currently approved to treat T2DM and may potentially be helpful in other insulin-resistant disorders (39). The efficiency of rosiglitazone to maintain DM under metabolic control is greater than glyburide and metformin (16). However, there may be an increased risk of cardiovascular disease in patients treated with rosiglitazone. Additionally, experimental and clinical evidence indicates that TZD use is associated with adverse effects on the skeleton, mainly in postmenopausal women with T2DM.

Osteoblasts and marrow adipocytes are derived from a common multipotential stem cell (MSC) progenitor. It has been hypothesized that the close relationship between these lineages underlies the reciprocal relationship between increased adipocytes and decreased bone formation that occurs during aging and with TZD therapy.

MSC fate is determined by expression and/or activation of specific transcription factors [i.e., Runx 2 and Osterix in the case of osteoblasts and CCAAT enhancer binding protein $\beta$ and peroxisome proliferator-activated receptor $\gamma$ (PPAR $\gamma$ ) in the case of adipocyte]. The transcriptional activity of PPAR $\gamma$ is induced by endogenous ligands such as prostaglandin $\mathrm{J}_{2}$ and oxidized fatty acids as well as by exogenous ligands such as the TZDs.

TZDs provoke bone loss in rats (40) and mice (41). BMD decreases in humans can be observed as early as 14 weeks after the treatment with rosiglitazone. Suppression in the production of biochemical markers of bone formation has also been observed after four weeks of treatment with rosiglitazone. The cellular basis of this skeletal re- 
sponse relates to the suppression of key osteoblastogenic transcription factors Runx2 and Osterix (41).

The accumulating evidences of TZD-induced skeletal toxicity prompted the pharmaceutical companies marketing these agents to analyze adverse event data collected during the performance of phase III trials. For example, the ADOPT study, a 4-year investigation designed to compared rosiglitazone, metformin and glyburide in the maintenance of glycemic control, showed that women, not men, on rosiglitazone had a higher incidence of appendicular fractures than women on metformin or glyburide. As this event was not a pre-specified issue, vertebral fracture data are not available. Although appendicular fracture is not the most typical osteoporotic fracture it seems to be more prevalent in diabetic populations. Data review was also performed on clinical trials of pioglitazone. Increased limb fractures were also observed in patients treated with this TZD, and once again this finding was only in female diabetic patients.

\section{Management of diabetic patients in thiazolidenedione therapy}

Health care providers need to be aware of the possibility of increased bone loss and fracture risk associated with TZD use. It is recommended that clinical fracture risk in patients be determined before initiation of TZD therapy. For postmenopausal women with DM, particularly those on TZD therapy, screening BMD may be useful. Osteoporosis therapy should be initiated in those women whose bone density and other risk factors place them at an increased risk for fracture.

\section{CONCLUSION}

Recent studies have shown that there is functional plasticity in bone, and that it is far greater than originally appreciated. Bone remodeling, the mechanism necessary to maintain bone strength, is sensitive to metabolic disarrangements such as DM and obesity. Surprisingly, recent studies have indicated that bone cells contribute to metabolic activity by the production of peptides such as osteocalcin that impacts insulin sensitivity and energy metabolism. These new networks will have implications at the bed side and are certain to be incorporated into newer strategies to treat both osteoporosis and diabetes.

Acknowledgments: Francisco J. A. de Paula was supported by a grant PDE 201650/2008-8 from CNPq "Conselho Nacional de Desenvolvimento Científico e Tecnológico”, DF, Brazil.
Disclosure: no potential conflict of interest relevant to this article was reported.

\section{REFERENCES}

1. National Center for Health Statistics 2004 - National Center for Health Statistics Survey. Available online at: www.cdc.gov/nchs/ products/pubs//pubd/hestats/obese/obse99.htm.

2. Monteiro CA, Conde WL, Popkin BM. Income-specific trends in obesity in Brazil: 1975-2003. Am J Public Health. 2007;97(10):1808-12.

3. Cowie CC, Rust KF, Ford ES, Eberhardt MS, Byrd-Holt DD, Li C, et al. Full accounting of diabetes and pre-diabetes in the U.S. population in 1988-1994 and 2005-2006. Diabetes Care. 2009;32(2):287-94.

4. Malerbi DA, Franco LJ. Multicenter study of the prevalence of diabetes mellitus and impaired glucose tolerance in the urban Brazilian population aged 30-69 yr. The Brazilian Cooperative Group on the Study of Diabetes Prevalence. Diabetes Care. 1992;15(11):1509-16.

5. U.S. Department of Health and Human Services 2004 Bone Health and Osteoporosis: A Report of the Surgeon General. U.S. Department of Health and Human Services, Rockville, MD, USA.

6. Pinheiro MM, Ciconelli RM, Martini LA, Ferraz MB. Clinical risk factors for osteoporotic fractures in Brazilian women and men: the Brazilian Osteoporosis Study (BRAZOS). Osteoporos Int. 2009;20(3):399-408.

7. Lee NK, Sowa H, Hino E, Ferron M, Ahn JD, Confavreux C, et al. Endocrine regulation of energy metabolism by the skeleton. Cell. 2007;130(3):456-69.

8. Pereira FA, de Castro JA, dos Santos JE, Foss MC, Paula FJ. Impact of marked weight loss induced by bariatric surgery on bone mineral density and remodeling. Braz J Med Biol Res. 2007;40(4):509-17.

9. Zhao LJ, Jiang H, Papasian CJ, Maulik D, Drees B, Hamilton J. Correlation of obesity and osteoporosis: effects of fat mass on the determinant of osteoporosis. J Bone Miner Res. 2008;23(1):17-29.

10. Janicka A, Wren TA, Sanchez MM, Dorey F, Kim PS, Mittelman SD, et al. Fat mass is not beneficial to bone in adolescents and young adults. J Clin Endocrinol Metab. 2007;92(1):143-7.

11. DeLaet $C$, Kanis JA, Oden A, Johanson H, Johnell O, Delmas $P$, et al. Body mass index as a predictor of fracture risk: a metaanalysis. Osteoporos Int. 2005;16(11):1330-8.

12. Siris ES, Miller PD, Barrett-Connor E, Faulkner KG, Wehren LE, Abbott TA, et al. Identification and fracture outcomes of undiagnosed low bone mineral density in postmenopausal women. Results from the National Osteoporosis Risk Assessment. JAMA. 2001;286(22):2815-22.

13. Schuit SCE, van der Klift M, Weel AE, de Laet CE, Burger H, Seeman $E$, et al. Fracture incidence and association with bone mineral density in elderly men and women: the Rotterdam Study. Bone. 2004;34(1):195-202.

14. Premaor MO, Pilbrow L, Tonkin C, Parker RA, Compston J. Obesity and fractures in postmenopausal women. J Bone Miner Res. 2009 Oct 12. [Epub ahead of print]

15. Rosen CJ, Bouxsein ML. Mechanism of disease: is osteoporosis the obesity of bone. Nat Clin Pract Rheumatol. 2006;2(1):35-43.

16. Kahn SE, Haffner SM, Heise MA, Herman VH, Holman RR, Jones $\mathrm{NP}$, et al. Glycemic durability of rosiglitazone, metformin or glyburide monotherapy. N Engl J Med. 2006;355(23):2427-43.

17. Picot J, Jones J, Colquitt JL, Gospodarevskaya E, Loveman E, Baxter $L$, et al. The clinical effectiveness and cost-effectiveness of bariatric (weight loss) surgery for obesity: a systematic review and economic evaluation. Health Technol Assess. 2009;13(41):1-190. 
18. Compston JE, Laskey MA, Croucher PI, Coxon A, Kreitzman S. Effect of diet-induced weight loss on total body bone mass. Clin Sci (Lond). 1992;82(4):429-32.

19. Ricci TA, Chowdhury HA, Heymsfield SB, Stahl T, Pierson RN Jr, Shapses SA. Calcium supplementation suppresses bone turnover during weight reduction in postmenopausal women. J Bone Miner Res. 1998;13(6):1045-50.

20. Fogelholm GM, Sievanen HT, Kukkonen-Harjula TK, Pasanen ME. Bone mineral density during reduction, maintenance and regain of body weight in premenopausal, obese women. Osteoporos Int. 2001;12(3):199-206.

21. Shapses SA, Von Thun NL, Heymsfield SB, Ricci TA, Ospina M, Pierson RN Jr, et al. Bone turnover and density in obese premenopausal women during moderate weight loss and calcium supplementation. J Bone Miner Res. 2001;16(7):1329-36.

22. Sjostrom L. Bariatric surgery and reduction in morbidity and mortality: experiences from the SOS study. Int J Obes. 2008;32(suppl 7):S93-7.

23. Goldner WS, O'Dorisio TM, Dillon JS, Mason EE. Severe metabolic bone disease as a long-term complication of obesity surgery. Obes Surg. 2002;12(5):685-92.

24. De Prisco C, Levine SN. Metabolic bone disease after gastric bypass surgery for obesity. Am J Med Sci. 2005;329(2):57-61.

25. Shapses SA, Riedt CS. Bone, body weight and weight reduction: what are the concern. J Nutr. 2006;136(6):1453-6.

26. Henriksen DB, Alexandersen $P$, Hartmann B, Adrian CL, Byrjalsen I, Bone HG, et al. Disassociation of bone resorption and formation by GLP-2: a 14-day study in healthy postmenopausal women. Bone. 2007;40(3):723-9.

27. Haderslev KV, Jeppesen PB, Hartmann B, Thulesen J, Sorensen HA, Graff J, et al. Short-term administration of glucagon-like peptide-2. Effects on bone mineral density and markers of bone turnover in short-bowel patients with no colon. Scand J Gastroenterol. 2002;37(4):392-8.

28. Berarducci A, Murr MM, Haines K. Risk and incidence of falls and skeletal fragility following Roux-en-Y gastric bypass surgery for morbid obesity. Osteoporos Int. 2007;18(S1): 201.

29. Forsen L, Meyer HE, Midthjell K, Edna TH. Diabetes mellitus and the incidence of hip fracture: results from the Nord-Trondelag $\mathrm{He}$ alth Survey. Diabetologia. 1999;42(8):920-5.
30. Cutrim DM, Pereira FA, de Paula FJ, Foss MC. Lack of relationship between glycemic control and bone mineral density in type 2 diabetes mellitus. Braz J Med Biol Res. 2007;40(2):221-7.

31. Schwartz AV, Sellmeyer DE, Ensrud KE, Cauley JA, Tabor HK, Schreiner $\mathrm{PJ}$, et al. Older women with diabetes have an increased risk of fracture: a prospective study. J Clin Endocrinol Metab. 2001;86(1):32-8.

32. Thorpe SR, Baynes JW. Maillard reaction products in tissue proteins: new products and new perspectives. Amino Acids. 2003;25(3-4):275-81.

33. Thornalley PJ, Langborg A, Minhas HS. Formation of glyoxal, methylglyoxal and 3-deoxyglucosone in the glycation of proteins by glucose. Biochem J. 1999;344:109-16.

34. Yao D, TaguchiT, MatsumuraT, Pestell R, Edelstein D, Giardino I, et al. High glucose increases angiopoietin-2 transcription in microvascular endothelial cells through methylglyoxal modification of mSin3A. J Biol Chem. 2007;282(42):31038-45.

35. Saito M, Fujii K, Soshi S, Tanaka T. Reductions in degree of mineralization and enzymatic collagen cross-links and increases in glycation-induced pentosidine in the femoral neck cortex in cases of femoral neck fracture. Osteoporos Int. 2006;17(7):986-95.

36. Saito M, Fujii K, Marumo K. Degree of mineralization-related collagen crosslinking in the femoral neck cancellous bone in cases of hip fracture and controls. CalcifTissue Int. 2006;79(3):160-8.

37. Ogawa N, Yamaguchi T, Yano S, Yamauchi M, Yamamoto M, Sugimoto T. The combination of high glucose and advanced glycation end-products (AGEs) inhibits the mineralization of osteoblastic MC3T3-E1 cells through glucose-induced increase in the receptor for AGEs. Horm Metab Res. 2007;39(12):871-5.

38. Yamamoto M, Yamaguchi T, Yamauchi M, Yano S, Sugimoto T. Serum pentosidine levels are positively associated with the presence of vertebral fractures in postmenopausal women with type 2 diabetes mellitus. J Clin Endocrinol Metab. 2008;93(3):1013-9.

39. Stout DL, Fugate SE. Thiazolidenediones for treatment of polycystic ovary syndrome. Pharmacotherapy. 2005;25(2):244-52.

40. Jennermann C, Triantafillou J, Cowan D, Pennink BGA, Connolly $\mathrm{KM}$, Morris DC. Effects of thiazolidinediones on bone turnover in the rat. J Bone Miner Res. 1995;10:S241. Abstract S361.

41. Afsham Ali A, Weinstein RS, Stewart SA, Parfitt M, Manolagas SC, Jilka RL. Rosiglitazone causes bone loss in mice by suppressing osteoblast differentiation and bone formation. Endocrinology. 2005;146(3):1226-35. 